\title{
INTERVENÇÕES DE ENFERMAGEM UTILIZADAS NO RASTREAMENTO PRECOCE DO CÂNCER CERVICO UTERINO: REVISÃO INTEGRATIVA
}

\author{
NURSING INTERVENTIONS USED FOR THE EARLY SCREENING \\ OF CERVICAL UTERINE CANCER: INTEGRATIVE REVIEW
}

\section{Luciene Rodrigues Barbosa $\mathrm{a}^{\mathrm{a}^{*}}$}

alucienerodriguesbarbosa@gmail.com

*FaculdadeAnhanguera - Guarulhos (SP), Brasil

Data de entrada do artigo: 26/01/2014 Data de aceite do artigo: 05/01/2015

\section{RESUMO}

Introduçáo: $\mathrm{O}$ câncer cérvico uterino $(\mathrm{CCU})$ é muito frequente em todo o mundo. Se diagnosticado precocemente, apresenta um potencial de prevenção e cura de aproximadamente 100\%. Objetivo: descrever o conhecimento nacional produzido sobre as intervençóes utilizadas na detecção precoce do CCU. Método: revisão de literatura. A coleta de dados foi realizada nas bases de dados LILACS e na biblioteca eletrônica SciELO, no mês de agosto de 2012 com a associação dos descritores "prevenção de câncer do colo uterino", "neoplasias do colo do útero" e "enfermagem". Para descrição das pesquisas selecionadas utilizou-se frequência absoluta (n), percentual (\%) e a organizaçáo dos dados por similaridade. Desenvolvimento: Todas as intervençôes, sejam elas sociais, comportamentais ou cognitivas, demonstraram proporcionar efeitos positivos no rastreamento precoce do CCU, no entanto, sugere-se combinação das intervençóes para ampliar a eficácia da abordagem. Conclusão: a estratégia primária e detecção precoce são os instrumentos mais adequados para reduzir a morbimortalidade ocasionada pela doença, e o enfermeiro, devido às inúmeras oportunidades de atuaçáo, demonstra ser o profissional adequado para auxiliar na minimização desta doença.

Palavras-chave: Prevenção de câncer do colo uterino; neoplasias do colo do útero; enfermagem.

\section{ABSTRACT}

Introduction: The cervical uterine cancer (CUC) is very prevalent throughout the world. If prematurely diagnosed, it presents a potential prevention and cure chance of approximately 100\%. Objective: To describe the national knowledge produced about the interventions used in the early detection of cervical cancer. Method: literature review. Data collection was performed on the data basis LILACS and SciELO electronic library in August of 2012, with the combination of the descriptors "prevention of cervical cancer", "cancer of the cervix" and "nursing". For a description of selected research we used absolute frequency (n), percentage (\%) and the organization of data by similarity. Development: All interventions, whether they were social, behavioral, or cognitive, proved to offer positive effects on early screening of the CUC, however, it is suggested a combination of interventions to increase the efficiency of the approach. Conclusion: The primary strategy and early detection are the most suitable instruments for reducing morbidity and mortality caused by the disease, and the nurse, because of its many opportunities for action, proves to be adequate to support the minimization of this disease.

Keywords: Prevention of cervical cancer; cervical neoplasia; nursing. 


\section{Introdução}

Segundo a Organização Mundial da Saúde (OMS) o câncer cérvico uterino (CCU) é muito frequente em todo o mundo. Se diagnosticado precocemente apresenta um potencial de cura de aproximadamente $100 \%$. É a segunda causa de óbito por neoplasias entre as mulheres, tendo sido responsável pelo óbito de 275 mil mulheres por ano ${ }^{1}$.

Em países desenvolvidos a prevalência de CCU tem apresentado uma redução significativa. A queda nesta taxa tenha sido, provavelmente, decorrente dos programas de detecção precoce e tratamento da doença. No entanto, em países emergentes, essa prevalência ainda encontra-se com taxa considerada alta, o que tem causando muita preocupação à saúde pública.

O câncer do colo do útero é uma afecção progressiva, que tem início com transformações das células intra-epiteliais que pode evoluir para um processo invasor num período que varia de 10 anos a 20 anos, estas células pré-cancerosas tendem a se espalhar mais profundamente no colo uterino e acabam se transformando em tumores malignos ${ }^{1}$. Por apresentar evolução lenta, muitas açóes podem ser desenvolvidas com objetivo de interromper o curso da doença ${ }^{2}$.

Um programa nacional para ser considerado eficaz para o desenvolvimento de ações de combate ao CCU deve ser composto por quatro componentes: prevenção, deteç̧ão precoce, diagnóstico/tratamento e cuidados paliativos ${ }^{3}$. Sendo que a prevenção primaria e deteç̧ão precoce a modalidade onde o profissional de enfermagem possui maior oportunidade para atuar na reduçáo dessa doença $a^{4,5}$.

A prevenção primária voltada para a detecção precoce inclui atividades educativas em saúde sexual, como palestras que abordam temas sobre prevenção, uso do preservativo e identificação de possíveis sintomas das doenças ginecológicas ${ }^{4}$. E a detecção precoce busca realizar estratégias de rastreamento da doença, voltada para grupos etários que apresentam um maior risco de adoecer, onde se busca esclarecer a estas mulheres os benefícios do exame e os sinais e sintomas do $\mathrm{CCU}^{5,6}$.

O Ministério da Saúde criou no Brasil, em 1998, um protocolo de Controle dos Cânceres de Colo de Útero e $\mathrm{Mama}^{7}$. Este preconiza que o exame para detecção precoce CUU seja realizado em todas as mulheres que já tiveram relaçóes sexuais, com especial atenção àquelas com idade entre 35 à 64 anos, devendo ser realizado uma vez por ano e após dois exames anuais consecutivos negativos, a cada três anos ${ }^{1}$.

Alguns estudos têm demonstrado o papel do enfermeiro na prevenção primária e detecção precoce desta doença, devido à oportunidade que este profissional possui em atuar nas diversas áreas da saúde onde se encontra a população feminina e também a ações educativas realizadas por este profissional ${ }^{8,9}$.

Diante do exposto, na tentativa de compreender as ações de enfermagem na prevenção e luta contra o CCU, este estudo teve como objetivo descrever o conhecimento nacional produzido sobre as intervençôes utilizadas na detecçáo precoce do CCU.

\section{Método}

Para viabilizar o desenvolvimento deste estudo, foi realizada uma revisão integrativa da literatura. A revisão integrativa é um método que proporciona uma síntese do conhecimento sobre determinada temática, fundamenta a prática ao conhecimento científico e permite a incorporaçâao de questôes relevantes da pesquisa ${ }^{10}$.

Para a elaboração da revisão integrativa foram percorridas as seguintes etapas: definição da questão norteadora (problema) e objetivos da pesquisa; o estabelecimento de critérios de inclusão e exclusão das publicaçôes (seleçáo da amostra); busca na literatura; análise e categorização dos estudos, apresentação e discussão dos resultados ${ }^{10}$.

O período da coleta de dados se desenvolveu de 27/01/2012 a 05/03/2012 nas seguintes bases de dados da Biblioteca Virtual da Saúde: Lilacs (Literatura Latino Americana e do Caribe em Ciencias da Saúde e na biblioteca eletrônica SciELO (Scientific Eletronic Library Online). Neste estudo optou-se por estas base de dados e biblioteca por compreender que atingem a literatura cientifica publicada nos países da America Latina e Caribe e também os artigos científicos na área da enfermagem produzidos no Brasil.

Destaca-se que foram utilizados os seguintes descritores: "prevenção de câncer do colo uterino", "neoplasias do colo do útero" e "enfermagem". E entre os descritores foi utilizado o conector boleano "and". Os critérios de inclusão das referências foram os seguintes: possuir ano de publicação entre os períodos de 2006 a 2011; artigos publicados em português, inglês e espanhol; possuir aderência ao objetivo proposto e devem abordar sobre a temática. Os critérios de exclusão foram: artigos que não estivessem publicados na íntegra; possuíssem repetição nas bases de dados e; não aderência às questôes relacionadas às intervençôes de enfermagem. E importante ressaltar que a busca foi realizada de forma ordenada, respectivamente, LILACS e SciELO. Os resumos foram avaliados, e as produçóes que atenderam os critérios de inclusão foram selecionadas para este estudo e lidas na íntegra.

Objetivando responder a questáo norteadora desta revisão elaborou-se um instrumento para a coleta das 
informaçóes, contendo os seguintes itens: título, autores, objetivo do estudo, método, periódico, ano de publicação, e principais resultados.

Após análise dos artigos, as intervenções foram categorizadas segundo um sistema de classificação utilizado anteriormente, em: sociais, comportamentais e cognitivas $^{11}$.

As intervenções sociais são aquelas que utilizam pessoas da comunidade, agentes comunitários ou profissionais de saúde para ampliar a adesão ao exame. Intervençóes comportamentais são aquelas que oferecem um estímulo para a realizaçáo do rastreamento do CCU (cartão ou agenda da mulher). Intervençóes cognitivas são medidas educativas onde a mulher recebe informaçóes sobre o exame de papanicolau e esclarece as suas dúvidas acerca do tema.

\section{Desenvolvimento}

Foram encontrados durante o estudo 40 artigos científicos, dos quais 06 apresentaram-se repetidos em mais de uma base de dados, portanto, das 40 referências encontradas somente 34 foram elencadas; destas somente 15 abordavam a temática proposta e foram utilizadas neste estudo.

A tabela a seguir mostra com propriedade o panorama das publicações:

Tabela 1: Distribuição das publicações selecionadas na base de dados e biblioteca eletrônica, 2012

\begin{tabular}{lccc}
\hline $\begin{array}{l}\text { Base de Dados } \\
\text { e Biblioteca } \\
\text { Eletrônica }\end{array}$ & $\begin{array}{l}\text { Temáticas } \\
\text { abordadas }\end{array}$ & \multicolumn{2}{c}{$\begin{array}{l}\text { Publicaçóes } \\
\text { selecionadas }\end{array}$} \\
SciELO & & $(\mathrm{n})$ & $(\%)$ \\
LILACS & 09 & 04 & 25,00 \\
Total & 31 & 11 & 75,00 \\
\hline
\end{tabular}

No que se refere aos periódicos dos artigos selecionados, foram identificados dez, com destaque para a Revista Texto Contexto Enfermagem, responsável por $20 \%$ das produçôes sobre o tema analisado.

Quanto ao período de publicação, constatou-se que os anos que apresentaram maior número de artigos científicos foram 2010 com cinco publicações, correspondendo 33,33\% de publicaçóes incluídas no estudo. $\mathrm{O}$ ano de 2011 apareceu com três publicaçóes, que corresponde a $20 \%$ por ano. Os anos de 2006, 2008 e 2009 possuem dois estudos cada, o que representa $13,33 \%$ das publicaçóes por ano. $\mathrm{O}$ ano de 2007 apareceu com um estudo, o que representa $6,66 \%$ ao ano.
Tabela 2: Distribuição dos artigos segundo os periódicos, 2012.

\begin{tabular}{lcc}
\hline Periódicos & $\begin{array}{c}\text { Artigos selecionados } \\
\text { (n) }\end{array}$ & (\%) \\
\hline Revista Texto Contexto Enfermagem & 03 & 20,00 \\
Revista Ciência e Saúde Coletiva & 02 & 13,33 \\
Revista Historia. Ciência Saúde & 02 & 13,33 \\
- Manguinhos & & \\
Revista Associação Médica Brasileira & 02 & 13,33 \\
Revista Saúde e Sociedade da USP & 01 & 6,66 \\
Revista de Pesquisa: cuidado & 01 & 6,66 \\
fundamental & & \\
Revista Ciência, Cuidado e Saúde & 01 & 6,66 \\
Revista Enfermagem da UFRJ & 01 & 6,66 \\
Revista de Pesquisa: cuidado & 01 & 6,66 \\
fundamental & & \\
Journal of Cancer Education & 01 & 6,66 \\
Total & 15 & 99,95 \\
\hline
\end{tabular}

Em relação ao delineamento de pesquisa, identificou-se que das 15 publicaçóes, nove utilizaram abordagem quantitativa $(60 \%)$, quatro qualitativa $(26,66 \%)$ e três documental (13,34\%).

A análise dos artigos demonstram que diversas estratégias de intervenção são utilizadas pelos enfermeiros para realizar a detecção precoce do CCU em mulheres em idade fértil como intervençóes sociais, comportamentais e cognitiva.

As intervençóes sociais estáo relacionadas à realização de açóes por profissionais especializados, como uma maneira de garantir um atendimento de qualidade no monitoramento do $\mathrm{CCU}^{8}$.

Em outra realidade, em uma pesquisa desenvolvida na Nigéria ${ }^{12}$, verificou-se que alguns enfermeiros declararam que desconheciam os tipos de câncer cervical e o desenvolvimento da técnica de coleta do material. Este estudo sugere que as instituiçóes onde são realizados os exames devem organizar periodicamente seminários e treinamentos com profissionais responsáveis pela coleta, abordando, nesta atividade, a importância da detecção precoce e da realização de atividade educacional em saúde com mulheres que buscam o serviço e saúde.

Neste sentido, observa-se que o preparo adequado do profissional inclui o conhecimento cientifico acerca do tema, o treinamento prático do procedimento e o estímulo a realização das atividades de educação em saúde, sendo estas consideradas fundamentais para a melhora na qualidade da coleta do material cervical e no aumento da detecçáo precoce da doença ${ }^{13}$.

As intervençóes comportamentais envolvem estratégias de comunicação (lembrete, cartão ou agenda da mulher) a utilização deste meio demonstrou ser eficaz no rastreamento precoce do CCU, essa abordagem tem 
como pressuposto que a mulher necessita de receber um estímulo (lembrete) para realizar o exame, esse estímulo pode ampliar a realização do exame e/ou retorno ${ }^{13}$.

Uma das estratégias utilizadas em um estudo ${ }^{14}$ foi a utilização de um cartão ou agenda da mulher, onde são anotados os exames realizados pela mulher, se ela foi buscar o resultado e passou na consulta de retorno. Assim a Equipe da Estratégia Saúde da Família pode monitorar estas mulheres, realizar a busca ativa e solicitar que esta compareça ao serviço de saúde quando necessário.

Nessa mesma pesquisa ${ }^{13}$ os enfermeiros afirmaram que conheciam o seu papél na Estratégia Saúde da Família na atenção a Saúde da Mulher, as atividades realizadas em suas áreas de abrangência e participavam diretamente de açóes preventivas e educativas desenvolvidas na comunidade. Demonstrando que o conhecimento dos profissionais e o reconhecimento do seu papel como educador foram fatores facilitadores para a realização do rastreamento do CCU, no entanto, esta mesma pesquisa identificou que algumas mulheres, mesmo recebendo o estímulo, não procuram o serviço de saúde para a realização do exame papanicolau.

As intervençóes cognitiva diz respeito as estratégias educativas (reunióes em grupo e folder educativo) onde são abordados questóes fundamentais como a importância da detecção precoce da doença, apesar de apresentar um impacto positivo no nível de conhecimento da mulher, nem sempre as informaçôes pode garantir a ida desta a unidade de saúde.

As reuniōes de grupo são medidas educativas que, por meio de discussão, permite a troca de informações, melhorando o conhecimento da mulher a respeito da realização do exame, e estimulando as demais mulheres do grupo a realizarem o papanicolau ${ }^{15}$.

Um estudo realizado em João Pessoa com mulheres diagnosticadas com câncer utilizou esta estratégia para identificar os sentimentos das pacientes ao receberem o diagnóstico clínico. ${ }^{14}$ Ao final, verificou-se que, ao serem abordadas sobre o tema, as mulheres ainda ficavam perturbadas emocionalmente. Nota-se a importância da atuação do profissional no momento do diagnóstico e durante o tratamento medicamentoso.

Como evidenciado neste estudo, algumas dificuldades relacionados a pacientes e profissionais podem ser resolvidas com intervençôes adequadas, no entanto, estas intervenções em saúde devem ser implementadas na comunidade de acordo com as características da população.

Outra questão importante para ser considerada na realização das intervençóes é o local onde a mulher está buscando atendimento. A ida da mulher a Unidade básica de saúde, seja para buscar atendimento para si própria ou para acompanhar alguém, deve ser vista como uma oportunidade para se discutir a realização do exame de papanicolau, especialmente para as pacientes que moram em regióes rurais. Deve-se aproveitar o momento em que a mulheres estáo mais abertas para receber intervençóes, que podem ser sociais, comportamentais ou cognitivas.

Outro aspecto relevante a ser considerado, é que, geralmente, o enfermeiro, durante consulta de enfermagem, tende a questionar somente a data da realização do último exame e o seu resultado. Contudo, somente questionar sobre a realização do exame não é suficiente para estimular a mulher a realizar um novo exame, o que sugere a importância de ser ofertado, também, informaçóes sobre o objetivo do exame, cuidados para o preparo e intervalo preconizado pelo MS (intervenção cognitiva), como são informações simples, provavelmente não levaria mais que alguns minutos para ser realizado. Além disso, caso a paciente se encontre em condiçôes de realizar o exame, deveria ser oportunizada, sempre que possível, a realizaçáo do procedimento neste momento para evitar que esta mulher, ao ir embora, não retorne para realizar o procedimento.

Neste caso, a intervenção comportamental parece ter um efeito melhor quando comparada à cognitiva, pois a oportunidade de disponibilidade do exame associado à ida desta mulher à unidade tende a aumentar a possibilidade de realização.

Observou-se que, na maioria dos estudos, a intervenção mais usada foi a cognitiva, com a utilização de folder educativo, distribuídos às mulheres na unidade de saúde ou durante a visita domiciliar. A utilização de folder educativo sem intervenção do enfermeiro, apesar de demonstrar uma melhora no nível de conhecimento das mulheres acerca do exame de papanicolau, não reduz o nível de ansiedade da mulher, produzindo, assim, pouco impacto no momento da procura do procedimento na unidade de saúde ${ }^{16}$.

No entanto, os estudos em que o profissional da saúde, por meio de reunióes em grupo, discutiu os medos e as dificuldades para realização do exame, ocorreu um aumento na taxa de realizaçáo do procedimento ${ }^{4,17,18}$.

Açóes educativas que permitem a interação entre profissional e o usuário do serviço, permite que o enfermeiro promova um ambiente acolhedor e a construção de vínculos com os participantes, passando a reconhecer sua comunidade e a estimular a mulher a comprometerse com seu próprio bem-estar ${ }^{9,19}$.

Uma mulher que anteriormente tenha se sentido constrangida na realização do exame de Papanicolau, ou que nunca o realizou, pode apresentar maior dificuldade de procurar espontaneamente o serviço de saúde. Esta situação fica ainda mais evidente quando há diferenças culturais ou de idioma (população indígena), o que necessitaria de uma estratégia que alcance toda comunidade $^{20}$. Em situaçóes como esta, podem ser utilizados 
outros meios de abordagem, como a utilização de um agente comunitário de saúde, líderes comunitários, interpretes (para pessoas leigas da comunidade indígena), dentre outros ${ }^{22}$.

\section{Considerações finais}

Este estudo evidenciou que a identificação da intervenção adequada sempre deve levar em consideração as características da comunidade, como etnia, condição socioeconômica, ambiente onde se encontra a mulher.

Todas as intervençôes, sejam elas sociais, comportamentais ou cognitivas, demonstraram proporcionar efeitos positivos no rastreamento precoce do CCU, no entanto, sugere-se combinação das intervençóes para ampliar a eficácia da abordagem. Ressalta-se que as intervenções descritas neste estudo são de fácil aplicabilidade e adaptação ao contexto local de cada área de abrangência.

Identificou-se que o enfermeiro tem um papel importante no rastreamento do CCU, pois exerce uma ação educativa ao esclarecer às mulheres a necessidade do exame de Papanicolau e de práticas sexuais seguras para prevenção do câncer do colo uterino.

Espera-se, com este estudo, estimular os enfermeiros a realizarem atividade de intervençóes, embasada no conhecimento científico que consolidem a sua prática diária.

\section{Referências}

1. World Health Organization,. International Agency for Research on Cancer. Globocan 2008. 2010 [acesso em: 25 jan. 2012]. Disponível em: http://globocan.iarc.fr/.

2. Galvão MTG, Freitas JG, Costa E, Lima ICV, Brito DMS, Diógenes MAR. Mulheres com HIV: características individuais e da prevenção de Câncer Cervical. Rev Rene. 2010;(11):99-108.

3. Organización Mundial de la Salud. Control integral del cáncer cervicouterino: guía de práticas esenciales. Geneva; 2007.

4. Casarin MR, Piccoli JCE. Educação em saúde para prevenção do câncer de colo do útero em mulheres do município de Santo Ângelo/RS. Ciênc Ssaúde Ccolet [periódico na Internet]. 2011 [acesso em: 23 set. 2012];16(9):39253932. Disponível em: http://www.scielo.br/pdf/csc/v16n9/ a29v16n9.pdf

5. Oliveira WA, Barbosa MA, Mendonça BOM, Silva AA, Santos LCF, Nascimento LCD. Adesão de mulheres de 18 a 50 anos ao exame colpocitológico na Estratégia Saúde da Família. Rev Eenf Rref [periódico na Internet]. 2012 [acesso em: 23 set 2012];(7):15-22. Disponível em: http://www. scielo.gpeari.mctes.pt/scielo.php?script=sci_arttext\&pi$\mathrm{d}=$ S0874-02832012000200002\&lng=pt

6. Anticaglia CM, Souza PRK, Raitz R. Conhecimento de estudantes universitários sobre HPV, sua relação com câncer de útero e métodos preventivos. Rev Bbras Cciênc Ssaúde. 2008 [acesso em: 23 set 2012];3(15). Disponível em: http:// seer.uscs.edu.br/index.php/revista_ciencias_saude/article/ view/536/381

7. Brasil. Ministério da Saúde, Secretaria de Atenção à Saúde, Departamento de Atençáo Básica. Controle dos cânceres do colo do útero e da mama. Brasília. 2006.

8. Rogers NM, Cantu AG. The nurse's role in the prevention of cervical cancer among underserved and minority populations. J Ccommun Health. 2009;(34):135-43.

9. Ferreira MLSM. Motivos que influenciam a -não realizaçáo do exame de papanicolau segundo a percepção das mulheres. Esc Anna Nery Rrev Eenferm. 2009 [acesso em: 23 set 2012]; 13(12):378-84. Disponível em: http://www. lume.ufrgs.br/bitstream/handle/10183/27055/000751961. pdf? sequence $=1$

10. Souza MT, Silva MD, Carvalho R. Revisão Integrativa: o que é e como fazer. Rev. Einstein [periódico na Internet]. 2010 [acesso em 12 set 2012];8(1):102-06. Disponível em: http://apps.einstein.br/revista/arquivos/PDF/1134Einsteinv8n1_p102-106_port.pdf

11. Yabroff KR, Mangan P, Mandelblatt J. Effectiveness of interventions to increase Papanicolau smear use. J Aam Bboard Ffam Mmed. 2003;16(3):188-203.

12. Amodele O, Aeyomoye AAA, Awodele F, Kwashi V, Awodele IO, Dolapo DC. A study on Cervical Cancer Screening amongst nurses in Lagos University Teaching Hospital, Lagos, Nigeria. Journal Ccanc Eeduc. 2011 [acesso em 03 out 2012];26(3):497-504. Disponível em: http://www.ncbi.nlm.nih.gov/pmc/articles/PMC3161190/ pdf/13187_2010_Article_187.pdf

13. Melo MCSC, Vilela F, Salimena AMO, Souza IEO. Enfermeiro e prevenção do Câncer do Colo do Útero: o cotidiano da Atenção Primária. Rev Bbras Ccancerol. 2012 [acesso em 28 out 2012];58(3):389-398. Disponível em: http://www. inca.gov.br/rbc/n_58/v03/pdf/08_artigo_enfermeiro_prevencao_cancer_colo_utero_cotidiano_atencao_primaria.pdf

14. Vasconcelos CTM, Damasceno MMC, Lima FET, Pinheiro AKB. Revisão integrativa das intervençóes de enfermagem utilizadas para detecção precoce do câncer cérvico-uterino. Rev Llatinoam Eenferm. 2011 [acesso em 28 out 2012];19(2):1-8. Disponível em: http://www.scielo.br/pdf/ rlae/v19n2/pt_28.pdf

15. Silva SS; Aquino TAA; Santos RM. O paciente com câncer: cognições e emoçōes a partir do diagnóstico. Revista Bbras Tter Ccogn. 2008 [acesso em: 23 set 2012];4(2):73-87. Disponível em: http://pepsic.bvsalud.org/pdf/rbtc/v4n2/ v4n2a06.pdf

16. Silva SR, Lício FC, Borges LV, Mendes LC, Vicente NG, Gomes NS. Atividades educativas na área da saúde da 
mulher: um relato de experiência. Rev Eenferm aAtenção Ssaúde. 2012;01(1):106-12.

17. Barbeiro FMS; Cortez EA. Conhecimento e práticas das mulheres acerca do exame Papanicolau e prevenção do câncer do colo uterino. Rev Ppesq Cuid Fundam. 2009;1(2):414-422.

18. Cruz LMB, Loureiro RP. A Comunicação na abordagem preventiva do câncer do colo do útero: Importância das influências histórico-culturais e da sexualidade feminina na adesão as campanhas. Saúde Soc. 2008 [acesso em 28 out 2012];17(2):120-131. Disponível em: http://www.scielo. br/pdf/sausoc/v17n2/12.pdf
19. Casarin MECR, Piccoli JCE. Educação em saúde para prevenção do câncer de colo uterino em mulheres o município de Santo Ângelo/RS. Ciênc Ssaúde Ccolet. 2011 [acesso em 09 nov 2012];16(9):3925-3932. Disponível em: http:// www.scielo.br/pdf/csc/v16n9/a29v16n9.pdf.

20. Cirino FMSB, Nichiata LYI, Borges ALV. Conhecimento, atitude e práticas na prevenção do câncer de colo uterino. Esc Anna Nery rRev Eenferm [periódico na Internet]. 2010 [acesso em 03 out 2012];14(1):126-134. Disponível em: http://www.scielo.br/pdf/ean/v14n1/ v14n1a19.pdf 